Available online at GSC Online Press Directory

GSC Biological and Pharmaceutical Sciences

e-ISSN: 2581-3250, CODEN (USA): GBPSC2

Journal homepage: https://www.gsconlinepress.com/journals/gscbps

(RESEARCH ARTICLE)

\title{
Severe maternal morbidity and intensive care in a public sector university hospital of Tunisia
}

\author{
Olfa Zoukar ${ }^{1}$, Sofiane Kouas ${ }^{2,}{ }^{*}$, Ines Zouari ${ }^{1}$, Mouna Gara ${ }^{3}$, Amel Khaskhoussi ${ }^{1}$ and Anis Haddad ${ }^{1}$ \\ ${ }^{1}$ Department of Gynecology and Obstetrics, Monastir Medical School, Monastir University, El Omrane Hospital of \\ Monastir-Monastir-Tunisia. \\ ${ }^{2}$ Department of Gynecology and Obstetrics, Monastir Medical School, Monastir University, Gynecology-Obstetric Service \\ Mahdia-Tunisia. \\ ${ }^{3}$ Department of Intensive care unit, Monastir Medical School, Monastir University, Fattouma Bourguiba Hospital of \\ Monastir-Tunisia.
}

Publication history: Received on 25 July 2020; revised on 04 August 2020; accepted on 06 August 2020

Article DOI: https://doi.org/10.30574/gscbps.2020.12.2.0241

\begin{abstract}
Recent years have been marked by a considerable reduction in maternal mortality rates in Tunisia. $60 \%$ of these deaths occur in intensive care units. Given the downward trend in maternal mortality rates, severe maternal morbidity is currently considered by several Western authors as a relevant indicator in the assessment of the quality of care delivered to parturients. As a result, we undertook a retrospective study of a population of patients in the gravidpuerperal state in need of a transfer from the maternity ward to the Surgical Intensive Care Department of the Monastir University Hospital between January 1, 2011 and December 31, 2017.
\end{abstract}

Keywords: Maternal morbidity; Intensive care; Indicator; Quality of care; Public hospital in Tunisia.

\section{Introduction}

According to the national survey of maternal mortality carried out in Tunisia between 1993 and 1994, maternal mortality rate (MMR) estimates were in the range of 68.9 / 100,000 live births. This finding [1] was at the origin of the implementation of a system for monitoring cases of maternal deaths with the aim to reduce them [1]. In addition, this system sets out to identify the main underlying causes of maternal deaths with the focus on avoidable ones so as to adopt appropriate measures to reduce them.

This system associated with the national perinatal program has certainly reduced the magnitude of this problem .With an MMR of 36 maternal deaths per 100,000 live births in 2007 [1], Tunisia became among the African countries with the lowest MMR. In our Maternity and Neonatology Center in Monastir, this rate was estimated at 29/100000 LB between 1999 and 2005 . However, Despite the great progress made over the last few decades, this rate still remains far away from those in the developed countries ( 12 maternal deaths per 100000 live births) [2].

Improving maternal health and reducing global maternal mortality by $75 \%$ by 2015 is one of the key priorities of The United Nations Millennium Development [3]. Tunisia joined this latest project and included it in its 10th Five-Year Plan with a target ratio of less than 25 per 100,000 by 2025.

\footnotetext{
${ }^{*}$ Corresponding author: Kouas Sofiane
} 
Surprisingly enough, $75.3 \%$ of these deaths were considered preventable [1] by early recognition of severe maternal complications and their adequate and timely management. It is clear, therefore, that among the actions to be undertaken to reduce MM, we must address the severe pregnancy- and childbirth-related maternal morbidity.

Elsewhere, if maternal mortality has been selected as a health status indicator, it may seem paradoxical in absolute terms, as the low number of maternal deaths does not allow definitive conclusions to be drawn [4]. For this reason, many authors are now attaching more importance to severe maternal morbidity (MM), which could be a relevant and adequate indicator of the quality of care provided to women during the pregnancy and puerperal period and thus constitute an intermediate indicator for measuring MM because the causes are super imposable [4].

If any pregnancy is likely to be marred by obstetric complications, they occur preferentially in the third trimester or in the peripartum period and often have an impact on the vital prognosis of the mother and the child. The transfer of the mother to intensive care is necessary when the situation is insufficiently or not controlled by an initial treatment administered at the maternity ward, and in the various cases where intensive monitoring of the patient is required.

These patients who are transferred from the obstetrical setting are significantly different from other patients in the intensive care unit and pose different problems of care to the resuscitator because of their physiological peculiarities and the medical disorders that are specific to pregnancy and childbirth [5]. Intensive care unit admission could therefore be considered as an indicator of severe maternal morbidity [6-7].

The main objective of this study is to evaluate this indicator, in our conditions of practice, through an analysis of the epidemiological, clinical, biological and evolutionary aspects of this population. Our second goal is to provide health decision-makers with the actions and resources they can focus on for planning and prevention.

\section{Material and methods}

This is a retrospective descriptive study carried out at The University Hospital of Monastir (Tunisia). It included all patients in the gravidum-puerpural state transferred from the maternity ward to the surgical resuscitation unit of the same hospital over a six-year period from January 1, 2011 to December 31, 2017.

To evaluate this severe morbidity in our conditions of practice, it seemed to us that it would be particularly interesting carry out an investigation on the causes of admission and the future of all parturients hospitalized in the intensive care unit.

In this work, the records of parturients transferred to intensive care units were reviewed to determine:

- The frequency and causes of transfer.

- The epidemiological and clinical particularities of this population.

- The interventions and therapies required to treat these women.

- The maternal-fetal prognosis in this group.

The present study was undertaken to examine obstetric admissions to the intensive care unit over a three-year period and to analyze the main causes of admission, clinical features, interventions, and the final outcome.

Although an average of 5,000 deliveries are performed per year in our level 3 maternity, it has only 2 operating rooms used for both obstetrical and gynecological surgical activities and does not have a recovery or intermediate resuscitation room. It constitutes the reference of the 9 peripheral maternities of the governorate of Monastir. In addition to all highrisk pregnancies, it receives all complicated cases during childbirth and postpartum.

The Monastir University Hospital is equipped with a multipurpose surgical intensive care unit. It has 12 beds only, eight of which are equipped with respirators. After delivery, our patients are transferred to the post-partum or post-operative wards of the Gynecology and Obstetrics Department. In cases requiring close monitoring or monitoring of vital functions, they will be transferred to the multipurpose surgical intensive care unit of the same facility. Newborns are supervised close to their mothers and, if necessary, are transferred to the pediatric ward (neonatal unit).

For each case, the following parameters were specified: 
- Socio-demographic data

- Pathological antecedents

- Data on the course of the current pregnancy, childbirth and the postpartum period.

- Neonatal data

These data were collected from:

- Mother-child health notebook,

- Medical records of hospitalization in the unit of high-risk pregnancies of our maternity,

- Obstetrical records of childbirth,

- Health files or letters of transfer of the peripheral maternities.

- Medical records and records of anesthesia,

- Medical charts and records of the pediatric ward.

Variables used for the survey:

- Maternal age, parity, antecedents, progress of pregnancy.

- Delivery mode: spontaneous or instrumental low pathway, caesarean section, urgency.

- Time of onset of complications: first, second, third trimester, postpartum.

- Main treatment modalities used at the maternity.

- $\quad$ Reason for transfer to the intensive care unit.

- Clinical examination upon arrival in intensive care unit, state of consciousness, spontaneous or controlled ventilation, shock.

- Main treatment modalities : controlled ventilation, vasoactive drugs, sedation T blood transfusion, hemodialysis ...

- Duration of hospitalization in intensive care unit, duration of ventilation.

- Mother's and a new born's prognosis.

The data were collected on previously validated data sheets, then entered and analyzed using SPSS 13.0 for windows. These data were the subject of a descriptive and analytical study.

Quantitative variables are presented as a mean and standard deviation, while qualitative variables are expressed in number and percentage or median and standard deviation.

\subsection{Population}

This study included all pregnant women transferred to surgical intensive care unit during pregnancy or within 42 days of delivery (Ectopic pregnancy, spontaneous miscarriage, voluntary or medical termination of pregnancy included). ).

This time frame was used with reference to the INSERM 2009 definition of maternal mortality [8].

We have deliberately excluded cases of thromboembolic complications that are usually transferred to the cardiac intensive care unit.

A case of severe obstetric morbidity was defined as any patient in a gravido-puerperal state requiring treatment in resuscitation unit or intensive care unit, regardless of the medical or surgical nature at any time during pregnancy, whatever the duration, during delivery, or after childbirth within less than 43 days. This timeframe was chosen because of its use in the definition of maternal mortality recommended by WHO and used in France [1]. A file was filled retrospectively by a qualified investigator (doctor or midwife) for all cases. This file included questions about the characters [9].

\section{Results}

During the study period, we recorded 32,250 live births and 263 cases of transfers of women in the gravid-puerperal state to the intensive care unit. All our patients were transferred postoperatively or in the postpartum period. This 
accounted for a resuscitation admission rate of $0.8 \%$ among live births and $7.2 \%$ among all admissions to the surgical intensive care unit (Table 1).

Depending on the year, the annual transfer number varied from 22 to 51 , with an average number of annual transfers of 35.6.

Table 1 Annual number of general and obstetric hospitalizations

\begin{tabular}{llll}
\hline Year & General Population & Obstetric Population & Frequency (\%) \\
\hline 2002 & 492 & 33 & 6.7 \\
2003 & 556 & 22 & 3.9 \\
2004 & 525 & 25 & 4.7 \\
2005 & 530 & 51 & 9.6 \\
2006 & 539 & 44 & 8.1 \\
2007 & 506 & 48 & 9.4 \\
2008 & 465 & 40 & 8.6 \\
Total & 3613 & 263 & 7.2 \\
\hline
\end{tabular}

\subsection{Main pathologies causing the transfer}

The observed causes of ICU transfer are summarized in Table II and are classified into four main etiological groups. They were dominated by hypertensive disorders that accounted for more than half of our transfers (Table 2).

Table 2 Distribution of patients by ICU admission causes.

\begin{tabular}{|l|l|l|}
\hline Etiology & Number & Percentage (\%) \\
\hline $\begin{array}{l}\text { Hypertensive } \\
\text { Pathology }\end{array}$ & 1 & 58.9 \\
\hline Hemorragic & 55 & \\
Pathology & 6 & 26.2 \\
\hline Cardio-respiratory & 9 & \\
Pathology & 2 & 10.3 \\
\hline Others & 7 & 4.6 \\
\hline Total & 1 & \\
\hline
\end{tabular}

The average age of our patients was $30.5 \pm 6$ years (range: 17 to 44 years) and the average parity was $2.3 \pm 1.6 .20 .5 \%$ had at least one medical or surgical history and $29.6 \%$ had an obstetrical history which were dominated by cardiac valvulopathies (8.3\%) and scarred uterus (15.6\%).Only $61 \%$ of patients had adequate prenatal follow-up according to our national perinatal program which included 4 consultations during pregnancy (Table 3).

The course of pregnancy was marked by the occurrence of at least one pathological disease in $24.6 \%$ of cases (Table 4). This was essentially in utero fetal death (6.5\%), the threat of preterm birth (5.7\%) and preeclampsia (4.5\%).It should be noted that in $60.7 \%$ of cases, patients were transferred from peripheral hospitals in the region for management of high-risk delivery or a pregnancy complication and only $29.6 \%$ of patients were hospitalized for stabilizing a pregnancyrelated pathology and scheduling delivery. 
Table 3 ICU Intake Cases and General Characteristics of the study population.

\begin{tabular}{|c|c|c|c|c|c|}
\hline & \multicolumn{4}{|c|}{ Main causes of ICU admissions } & \multirow{2}{*}{$\begin{array}{l}\text { Total } \\
\text { N(\%) }\end{array}$} \\
\hline & $\begin{array}{l}\text { Hemorragic } \\
\text { disease }\end{array}$ & $\begin{array}{l}\text { Hypertensive } \\
\text { disease }\end{array}$ & $\begin{array}{l}\text { Cardio- } \\
\text { respiratory }\end{array}$ & Others & \\
\hline $\begin{array}{l}\text { Age (years } \\
<25 \\
{[25-35]} \\
>35\end{array}$ & $\begin{array}{l}10 \\
43 \\
16\end{array}$ & $\begin{array}{l}36 \\
85 \\
34\end{array}$ & $\begin{array}{l}4 \\
17 \\
6\end{array}$ & $\begin{array}{l}2 \\
8 \\
2\end{array}$ & $\begin{array}{l}\mathbf{3 0 , 5} \mathbf{5 6} \\
52(19.8) \\
153(58.2) \\
58(22.1)\end{array}$ \\
\hline $\begin{array}{l}\text { Parity } \\
\leq 2 \\
>2\end{array}$ & $\begin{array}{l}35 \\
34\end{array}$ & $\begin{array}{l}108 \\
47\end{array}$ & $\begin{array}{l}18 \\
9\end{array}$ & $\begin{array}{l}8 \\
4\end{array}$ & $\begin{array}{l}2,3 \pm 1,6 \\
169(64.3) \\
94(35.7)\end{array}$ \\
\hline $\begin{array}{l}\mathrm{BMI}\left(\mathrm{Kg} / \mathrm{m}^{2}\right) \\
\leq 30 \\
>30\end{array}$ & - & $\begin{array}{l}- \\
18\end{array}$ & - & $\begin{array}{l}- \\
3\end{array}$ & $\begin{array}{l}31.3 \pm 5.4 \\
- \\
28\end{array}$ \\
\hline $\begin{array}{l}\text { Antecedents } \\
\text {-Cardiopathy } \\
\text {-Asthma } \\
\text {-Systemic diseases } \\
\text {-Diabetes } \\
\text {-Cesarian }\end{array}$ & $\begin{array}{l}0 \\
1 \\
1 \\
0 \\
16\end{array}$ & $\begin{array}{l}9 \\
0 \\
1 \\
5 \\
15\end{array}$ & $\begin{array}{l}13 \\
1 \\
1 \\
0 \\
7\end{array}$ & $\begin{array}{l}0 \\
0 \\
3 \\
0 \\
3\end{array}$ & $\begin{array}{l}22(8.3) \\
2(0.7) \\
6(2.3) \\
5(1.9) \\
41(15.6)\end{array}$ \\
\hline
\end{tabular}

Table 4 Causes of ICU admission and progress of pregnancy.

\begin{tabular}{|c|c|c|c|c|c|}
\hline \multirow[b]{2}{*}{ Delivery } & \multicolumn{4}{|c|}{ Main cause of ICU admission } & \multirow{2}{*}{$\begin{array}{l}\text { Total } \\
\text { N (\%) }\end{array}$} \\
\hline & Hemorragic & Hypertensive & $\begin{array}{l}\text { Cardio- } \\
\text { respiratory }\end{array}$ & Others* & \\
\hline $\begin{array}{l}\text { Delivery term } \\
<34 \mathrm{SA} \\
34-37 \mathrm{SA} \\
>37 \mathrm{SA}\end{array}$ & $\begin{array}{l}13 \\
14 \\
42\end{array}$ & $\begin{array}{l}41 \\
59 \\
55\end{array}$ & $\begin{array}{l}3 \\
17 \\
7\end{array}$ & $\begin{array}{l}1 \\
6 \\
5\end{array}$ & $\begin{array}{l}35,6 \pm 4,8 \\
58(22.1) \\
96(36.5) \\
109(41.4)\end{array}$ \\
\hline $\begin{array}{l}\text { Mode of delivery } \\
\text {-SVD } \\
\text {-IVD } \\
\text {-Urgent CS } \\
\text {-Scheduled CS } \\
\text {-Pregnancy medical breakdown }\end{array}$ & $\begin{array}{l}16 \\
7 \\
43 \\
2 \\
2\end{array}$ & $\begin{array}{l}14 \\
2 \\
133 \\
5 \\
1\end{array}$ & $\begin{array}{l}1 \\
1 \\
12 \\
12 \\
1\end{array}$ & $\begin{array}{l}1 \\
0 \\
5 \\
5 \\
0\end{array}$ & $\begin{array}{l}32(12.2) \\
10(3.8) \\
193(73.4) \\
24(9.1) \\
4(1.5)\end{array}$ \\
\hline $\begin{array}{l}\text { Complication term } \\
\text {-First trimester } \\
\text {-Second trimester } \\
\text {-Third trimester } \\
\text {-Post partum }\end{array}$ & $\begin{array}{l}3 \\
2 \\
31 \\
33\end{array}$ & $\begin{array}{l}0 \\
2 \\
138 \\
15\end{array}$ & $\begin{array}{l}0 \\
1 \\
11 \\
15\end{array}$ & $\begin{array}{l}0 \\
0 \\
6 \\
6\end{array}$ & $\begin{array}{l}3(1.1) \\
5(1.9) \\
186(70.7) \\
69(26.2)\end{array}$ \\
\hline
\end{tabular}


The mean term of delivery was 35.6 weeks of amenorrhea (Table 5). It was high in $77.2 \%$ of cases, $89 \%$ of which were urgent cesarean sections. These were indicated primarily for severe pre-eclampsia, third trimester hemorrhage or decompensated heart disease. The initial cause of transfer occurred mainly in the third trimester (70.7\%) and in the postpartum period (26.2\%). It was in the first trimester for 3 cases of hemorrhagic shock secondary to 2 terminated ERGs and one case of multiple uterine perforations following aspiration of the uterine cavity. Hemostasis hysterectomy was indicated to save the mother in $6.8 \%$ of cases with haemorrhage of delivery.

Hypertensive pathology was the leading cause of ICU admission because of the high number (36.5\%) of cases of severe pre-eclampsia requiring close monitoring in the postpartum period. The pathologies requiring the transfer to the intensive care unit were essentially hypertensive (59\%), haemorrhagic $(26.2 \%)$ and cardio-respiratory (10.2\%) pathologies (Table 6).

Table 5 Causes of ICU admissions and characteristics of childbirth.

\begin{tabular}{llllll}
\hline \multirow{2}{*}{$\begin{array}{l}\text { Course of } \\
\text { Pregnancy }\end{array}$} & \multicolumn{2}{l}{ Main Cause of ICU admission } & & $\begin{array}{l}\text { Total } \\
\text { n (\%) }\end{array}$ \\
\cline { 2 - 5 } & Hemorragic & Hypertensive & $\begin{array}{l}\text { Cardio- } \\
\text { Respiratory }\end{array}$ & Others & \\
\hline $\begin{array}{l}\text { Follow up } \\
\text { (consultations) }\end{array}$ & & & & $4.5 \pm 1.5$ \\
$<4$ & 33 & 36 & 5 & 5 & $79(30)$ \\
$\geq 4$ & 36 & 119 & 22 & 7 & $184(70)$ \\
Course & & & & & \\
- anemia & 30 & 41 & 14 & 2 & $87(34.5)$ \\
-chronic hypertension & 4 & 12 & 0 & 0 & $16(6.1)$ \\
- diabetes & 5 & 4 & 1 & 2 & $12(4.6)$ \\
- retro placental hematoma & 8 & 9 & 0 & 0 & $17(6.5)$ \\
-placenta praevia & 8 & 0 & 0 & 0 & $10(3.8)$ \\
- twins & 0 & 7 & 1 & 0 & $8(3.1)$ \\
- macrosomia & 7 & 8 & 1 & 1 & $17(6.5)$ \\
- IUFD & 10 & 4 & 3 & 0 & $17(6.5)$ \\
- others* & 4 & 1 & 0 & 1 & $5(1.9)$ \\
Hospitalisation & 34 & 70 & 20 & 7 & $131(49.8)$ \\
\hline
\end{tabular}

Table 6 Anaesthetic Evaluation of Patients by Cause of Admission

\begin{tabular}{llllll}
\hline Delivery & \multicolumn{2}{l}{ Main Cause of ICU admission } & \multicolumn{2}{l}{ Total } \\
\cline { 2 - 4 } & hemorrhagic & hypertensive & $\begin{array}{l}\text { Cardio- } \\
\text { respiratory }\end{array}$ & Others & \\
\hline ASA & & 138 & 12 & 7 & $223(84.8)$ \\
1 & 66 & 15 & 6 & 4 & $27(10.3)$ \\
2 & 2 & 2 & 9 & 1 & $13(4.9)$ \\
3 & 1 & $4,6[0-17]$ & $8[6-10]$ & $14[3-31]$ & $6.6[0-31]$ \\
APACHE II & & & & & \\
M [min-max] & $5,8[1-17]$ & $14,9[13-15]$ & $14[7-15]$ & $9,5[4-15]$ & $14.7[3-15]$ \\
Glasgow & & &
\end{tabular}


11 Uterine rupture and 9 low genital lesions.

In all cases, the first therapeutic care was started in the delivery room or in the operating room of our maternity department before the transfer.

At admission to the intensive care unit, the majority of our patients were classified as ASA1 (84.8\%) or ASA 2 (10.3\%) and were mainly represented by hypertensive and haemorrhagic pathology, whereas ASA 3 (4.9\%) was dominated by cardiovascular pathology (9cas / 13). Glasgow and APACHE II scores averaged 14.7 and 6.66 (Table 6).

The main systemic complications at the origin of the transfer or those observed in the intensive care unit were shock (29.3\%), acute renal failure (11\%), disseminated intravascular coagulation (8.7\%), acute pulmonary edema (3.4\%) and acute respiratory distress syndrome (8.7\%). These complications led to multiple visceral failures (Table 7) mainly cardiopulmonary $(13.3 \%)$, hematologic $(11.8 \%)$ and hepatic $(6.8 \%)$.

Table 7 Distribution of patients according to systemic complications and visceral failures.

\begin{tabular}{lll}
\hline Complications & Number & Frequency (\%) \\
\hline State of shock & 77 & 29.3 \\
Hemorrhagic & 58 & 22 \\
Cardiogenic & 14 & 5.3 \\
Septic & 4 & 1.5 \\
anaphylactic & 1 & 4 \\
Acute renal failure & 31 & 11.8 \\
DIVC & 23 & 8.7 \\
APO & 9 & 3.4 \\
Cardiogenic & 6 & 2.3 \\
lesionnel & 3 & 1.2 \\
ARDS & 23 & 8.7 \\
Visceralfailures & 100 & 38.1 \\
Cardio-pulmonary & 35 & 13.3 \\
Hematologic & 31 & 11.8 \\
Hepatic & 18 & 6.8 \\
Neurological & 8 & 3 \\
Renal & 8 & 3 \\
\hline
\end{tabular}

Therapeutically (Table 8), apart from caesarean section for maternal rescue, surgical treatment was required in 28 cases. Two patients with hemostasis disorders had to be reoperated on after haemostatic hysterectomy for parietal hematoma.

The main medical therapies started at the maternity ward and continued during the ICU stay were magnesium sulphate and Nicardipine, followed by the transfusion of red blood cells and coagulation factors. The use of vasoactive drugs was necessary in 34 cases including 15 cases for hemorrhagic shock.

Artificial ventilation was required in 18 cases with an average duration of $22 \pm 8$ hours. In one case transferred from a peripheral maternity hospital for hemorrhagic shock following uterine rupture and complicated cerebral hypoxia, respiratory assistance was provided for six days.

Five patients including two cases of HELLP syndrome and three cases of retro-placental hematoma with defibrination syndrome required haemodialysis sessions. 
Table 8 Principal therapeutic modalities.

\begin{tabular}{|c|c|c|}
\hline therapeutic & Number & $\begin{array}{l}\text { Percentage } \\
(\%)\end{array}$ \\
\hline Surgical Treatment & 28 & 10.6 \\
\hline Laparotomy* & 4 & 1.5 \\
\hline Hysterectomy & 19 & 7.2 \\
\hline vascular Ligatures & 3 & 1.1 \\
\hline Reoperating & 2 & 0.7 \\
\hline \multicolumn{3}{|l|}{ Medical treatment } \\
\hline Antihypertensive Treatment & 153 & 58.2 \\
\hline Sulfate magnesium & 155 & 59 \\
\hline Sulprostone (Nalador) & 35 & 13.3 \\
\hline Red cell Transfusion & 64 & 24.3 \\
\hline Coagulation factors & 59 & 22.4 \\
\hline Vasoactive drugs & 34 & 13 \\
\hline Artificial ventilation & 18 & 6.8 \\
\hline Hemodialysis & 5 & 1.9 \\
\hline
\end{tabular}

Changes in maternal status were favorable and without sequelae in $94 \%$ of cases and unfavorable in $6 \%$ of cases. Five patients died, representing a mortality rate of $1.9 \%$ of the cases included in our series and a maternal mortality rate of 15 per 100,000 live births. This rate is lower than the national rate (47.9 per 100,000 live births), and far lower than those in Third World countries but still higher than those in Western series.

At the fetal level, perinatal morbidity was dominated by prematurity (54.4\%) and acute fetal distress (32.1\%). We counted 224 live births, including seven twin births, 13 deaths in the neonatal period and seven per capita deaths. Perinatal mortality would therefore be 81 per 1000 births.

\section{Discussion}

The overall admission rate to the ICU of 7.2\% was higher than those reported in other studies in the obstetric intensive care unit, ranging from $0.9 \%$ to $1.7 \%$ [6]. Nevertheless, bed availability and ease of access are known factors in significantly affecting the number of admissions to these units. This study confirmed the high prevalence of cesarean deliveries (77.2\%) in SMM cases admitted to ICU, which is consistent with published data $(50 \%-80 \%)[6,8,9,10]$. The average length of stay in intensive care unit was 5 days, which is reported to be between 2 and 6.6 days in other studies $[8,9]$. This relatively short period of time compared to clinical / surgical ICUs may result primarily from the transient nature of obstetric complications, which usually disappear after pregnancy [9]. The epidemiologic profile of women is consistent with previously reported data, according to which, patients were young ( $30.5 \pm 6$ years), with low parity ( 2.3 \pm 1.6 ). $20.5 \%$ of them had at least one medical or surgical history and $29.6 \%$ had an obstetric history, and were admitted to an intensive care unit for mainly hypertensive (59\%), hemorrhagic (26.2\%) ) and cardio-respiratory $(10.2 \%)$.

Inter-hospital ambulance transfer occurred in $60.7 \%$ of cases, patients were transferred from hospitals in the outlying areas for management of high-risk delivery or a pregnancy complication and only 29 (6\%) of patients were hospitalized for stabilizing a pregnancy-related pathology and scheduling delivery.

Factors contributing to the increased severity of the disease could be delays in care, diagnosis, therapy or transportation, or difficulties in accessing an intensive care unit bed [1]. The clinical condition of the patient at admission and the delay in appropriate health care at the maternity unit of origin, as well as the conditions of the transfer itself, probably contributed to the increased morbidity among transferred patients. Although a centralized system has been established in the region to manage bed allocation in cases of serious obstetric complications, there are still difficulties and delays in access, factors that must be taken into account in any future restructuring of emergency obstetric care. Data from the literature show that approximately $25 \%$ of maternal deaths and MM cases are preventable 
and depend on the quality of care and the adoption of appropriate interventions [12]. Training programs for the recognition and early management of pregnancy complications by maternity professionals have been shown to reduce morbidity and its consequences $[11,12,13]$. Perinatal and intensive care guidelines produced by a regional organization with medical regulations can improve morbidity [13]. The ICU mortality rate was $1.9 \%$ of the cases included in our series and a maternal mortality rate of 15 per 100,000 live births. This rate is lower than the national rate (47.9 per 100,000 live births), and far lower than those in Third World countries but still higher than those in Western series.

However, the characteristics of the population of women admitted to obstetric resuscitation are different from those of clinical / surgical units [6,8]. This is likely to be influenced by their generally younger age and younger people recover faster than older people with more complex health histories. As a result, it is difficult to interpret the comparative analysis between mortality rates observed in these units. However, easier access to intensive care beds enables doctors to optimize care and quickly reach diagnoses in MM cases, thus, avoiding complications and ensuring faster recovery [3]. In keeping with recently published data, the majority of admissions to this obstetric intensive care unit were due to obstetric complications mainly hypertensive disorders, hemorrhage, and infectious complications [3, 10, 12]. They have also been reported as the leading causes of maternal mortality in low-income countries [1]. In this study, they accounted for $50 \%$ of all deaths. The use of the mortality / morbidity ratio makes it possible to calculate the effective contribution of any given morbidity to maternal mortality.

As this is a university teaching hospital, clinicians and specialized surgeons are available when needed, in addition to intensive care specialists and obstetricians who are permanently present. The evaluation of obstetrical complications, classified by cause, gave the following reports: The main systemic complications at the origin of the transfer or which were observed in the intensive care unit were the state of shock (29.3\%). acute renal failure (11\%), disseminated intravascular coagulation (8.7\%), acute pulmonary edema (3.4\%) and acute respiratory distress syndrome $(8.7 \%)$. These complications resulted in multiple visceral failures mainly cardiopulmonary (13.3\%), hematologic (11.8\%) and hepatic $(6.8 \%)$.

The main medical therapies started at the maternity ward and continued during the ICU stay were Nicardipine and magnesium sulphate, followed by the transfusion of red blood cells and coagulation factors. The use of vasoactive drugs was necessary in 34 cases including 15 cases of hemorrhagic shock. Artificial ventilation was required in 18 cases with an average duration of $22 \pm 8$ hours. In one case transferred from a peripheral maternity for hemorrhagic shock following a uterine rupture and complicated cerebral hypoxia, the respiratory assistance was provided for 6 days.Five patients including 2 cases of HELLP syndrome and 3 cases of Retro-placental hematoma with defibrination syndrome required Hemodialysis sessions. These results are consistent with previously published data $[10,12]$.

The need for more interventions and procedures in deceased women, as well as a higher total maximum SOFA score in this group, reflects attempts to maintain body homeostasis in the most severe cases. Multi-systemic organ failure was the leading cause of death in the majority of women, and this finding is also consistent with those of previous studies $[3,10]$.

\section{Conclusion}

The findings of this study indicate the need for political and social action for the implementation of reproductive health measures, including awareness of the need for obstetric intensive care beds in maternity wards; and improving the strategy for managing high-risk pregnancies. Currently, it is not possible to generalize these results to the whole country, as they could be specific to the region studied. It is not illogical to assume that these issues are relevant to other low-income countries, but each area should be considered before implementing any changes. The SOFA score can be a useful tool for assessing the severity and prognosis of MM cases. Establishing uniform international criteria for the definition of MMS and the adoption of the mortality / morbidity ratio as part of an audit system can help focus efforts to maximize pregnancy care, particularly in low income countries.

\section{Compliance with ethical standards}

\section{Acknowledgments}

We thank all the authors who participated in this work which will serve as a reference for making future effective and appropriate decisions. 


\section{Disclosure of conflict of interest}

The authors declare that there is no conflict of interest regarding the publication of this paper.

\section{Statement of informed consent}

Informed consent was obtained from all individual participants included in the study.

\section{References}

[1] La morbidité maternelle grave Sonia Ben Hamouda, Héla Khoudayer, Héla Ben Zina, Abdelwaheb Masmoudi, Rachida Sfar. La Revue Sage-Femme, 21-26.

[2] Morbidity and mortality of patients with preeclampsia or HELLP syndrome transferred in intensive care. Sabbah-Briffaut E, Bourzoufi K, Fourrier F, Subtil D, Houfflin-Debarge V, Deruelle P. (2009). Presse Med, 38(6), 872-80.

[3] Objectifs du Millénaire pour le développement - Indicateurs. Genève, Organisation mondiale de la Santé, (2004).

[4] Predictors of maternal mortality among critically ill obstetric patients.

Adeniran AS, Bolaji BO, Fawole AA, Oyedepo00.Malawi Med J. 2015 Mar; 27(1)

[5] Maternal critical care: what can we learn from patient experience? Hinton L, Locock L, Knight M.BMJ Open. 2015 Apr 27;5(4):e006676.

[6] Audit of severe acute maternal morbidity describing reasons for transfer and potential preventability of admissions to ICU.

Lawton BA, Wilson LF, Dinsdale RA, Rose SB, Brown SA, Tait J, Coles CL, McCaw A.Aust N Z J ObstetGynaecol. 2010 Aug; 50(4):346-51.

[7] Provision of critical care services for the obstetric population.

Sultan P, Arulkumaran N, Rhodes A.BestPract Res ClinObstetGynaecol. 2013 Dec; 27(6):803-9.

[8] Factors associated with maternal death in women admitted to an intensive care unit with severe maternal morbidity.

Oliveira Neto AF, Parpinelli MA, Cecatti JG, Souza JP, Sousa MH.Int J Gynaecol Obstet. 2009 Jun;105(3):252-6. doi: 10.1016/j.ijgo.2009.01.025. Epub 2009 Apr 1.

[9] Epidemiology of maternal morbidity and mortality AdiHirshberg, Sindhu K. Srinivas. Seminars in Perinatology, October 2017; Pages 332-337

[10] Severe maternal morbidity in a general intensive care unit in Nigeria: clinical profiles and outcomes

S. igbaruma, B. olagbuji, A. aderoba, W. kubeyinje, C. imarengiaye. International Journal of Obstetric Anesthesia, December 2016; Pages 39-44

[11] Maternal mortality and morbidity: Epidemiology of intensive care admissions in pregnancy

H. Senanayake, T. Dias, A. Jayawardena. Best Practice \& Research Clinical Obstetrics \& Gynecology, December 2013; Pages 811-820

[12] Establishment of a national severe maternal morbidity preventability review in New Zealand Evelyn Jane MacDonald, Stacie E. Geller, Beverley Lawton. (2016). International Journal of Gynecology \& Obstetrics, 120-123.

[13] Factors associated with maternal death in women admitted to an intensive care unit with severe maternal morbidity.

Antonio F, Oliveira Neto, Mary A, Parpinelli José G, Cecatti João P and Souza Maria H. (2009).Sousa. International Journal of Gynecology \& Obstetrics, 252-256.

\section{How to cite this article}

Zoukar O, Kouas S, Zouari I, Gara M, Khaskhoussi A and Haddad A. (2020). Severe maternal morbidity and intensive care in a public sector university hospital of Tunisia. GSC Biological and Pharmaceutical Sciences, 12(2), 64-73. 